University of Nebraska - Lincoln

DigitalCommons@University of Nebraska - Lincoln

Faculty Papers and Publications in Animal

Science

Animal Science Department

July 2005

\title{
Fertility of yearling beef bulls during mating
}

R. W. Ellis

University of Nebraska-Lincoln

Gary P. Rupp

University of Nebraska-Lincoln, grupp1@unl.edu

P. J. Chenoweth

Kansas State University, Manhattan

L. V. Cundiff

USDA, ARS, U.S. Meat Animal Research Center

D. D. Lunstra

Kansas State University, Manhattan

Follow this and additional works at: https://digitalcommons.unl.edu/animalscifacpub

Part of the Animal Sciences Commons

Ellis, R. W.; Rupp, Gary P.; Chenoweth, P. J.; Cundiff, L. V.; and Lunstra, D. D., "Fertility of yearling beef bulls during mating" (2005). Faculty Papers and Publications in Animal Science. 112.

https://digitalcommons.unl.edu/animalscifacpub/112

This Article is brought to you for free and open access by the Animal Science Department at DigitalCommons@University of Nebraska - Lincoln. It has been accepted for inclusion in Faculty Papers and Publications in Animal Science by an authorized administrator of DigitalCommons@University of Nebraska - Lincoln. 


\title{
Fertility of yearling beef bulls during mating
}

\author{
R.W. Ellis ${ }^{\text {a,* }}$, G.P. Rupp ${ }^{\text {a }}$, P.J. Chenoweth ${ }^{\mathrm{b}}$, L.V. Cundiff ${ }^{\mathrm{c}}$, \\ D.D. Lunstra ${ }^{\mathrm{c}}$

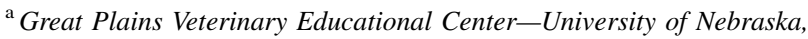 \\ Clay Center, NE 68933, USA \\ ${ }^{\mathrm{b}}$ College of Veterinary Medicine-Kansas State University, \\ Manhattan, KS 66506, USA \\ ${ }^{\mathrm{c}}$ USDA, ARS, U.S. Meat Animal Research Center, Clay Center, \\ NE 68933, USA
}

\begin{abstract}
Crossbred (Bos taurus) yearling beef bulls were assessed for breeding soundness and physical traits prior to multi-sire natural mating at pasture. Bulls $(n=60)$ were assigned to six groups of nine or 10 bulls and two bull-groups were rotated on 14-day intervals during a 63-day mating season in each breeding herd $(n=3)$ of $191-196$ cows. The remaining bulls $(n=14)$ were maintained under similar environmental conditions without mating exposure. Bulls were observed during mating and assessed for breeding soundness and changes following mating. Bulls used for breeding (UFB) lost $77 \mathrm{~kg}$ of body weight and declined from body condition scores of 6 to 4.5 , whereas bulls not used for breeding (NUB) maintained body condition scores of 6 and gained $27 \mathrm{~kg}$. The UFB bulls incurred a $75 \%$ total injury rate with $63 \%$ incidence of lameness and $12 \%$ incidence of reproductive injuries, resulting in a $22 \%$ attrition rate. Only $45 \%$ were physically sound at the end of mating. Scrotal circumference declined in UFB bulls (-4.58\%) and increased in NUB bulls (2.49\%). From the $98 \%$ BSE-satisfactory rate (UFB) prior to breeding, only $61 \%$ were BSE-satisfactory post-breeding. The NUB bulls declined from 57 to $36 \%$ satisfactory. The BSE classification was influenced by significant increases in abnormal spermatozoa (primary and secondary), which was significantly associated with injuries incurred during mating. Group and breed differences in injury rates and BSE-status following mating were evident. Environmental conditions and mating activity influenced bull seminal quality and physical condition. Pregnancy rates in all three breeding herds (91-96\%) were similar, with
\end{abstract}

\footnotetext{
A contribution of the University of Nebraska Agricultural Research Division, Lincoln, NE 68583. Journal Series No. 14511.

* Corresponding author. Tel:: +1 402762 4513; fax: +1 4027624509 .

E-mail address: rellis@gpvec.unl.edu (R.W. Ellis).
} 
insignificant differences between bull-groups; the effects of physical and reproductive changes on individual bull fertility were immeasurable.

(C) 2005 Elsevier Inc. All rights reserved.

Keywords: Bull; Breeding soundness evaluation; Fertility; Breeding injuries

\section{Introduction}

Yearling bulls are an important component of natural service mating in North American cattle operations and a Breeding Soundness Evaluation (BSE) is the principle method employed to assess the general reproductive potential of bulls. The BSE, when conducted within the guidelines of the Society for Theriogenology [1], assesses the current physical and reproductive status of bulls and allows for screening and selection of bulls with acceptable fertility-potential. Regarding yearling bulls, the BSE further serves to measure the pubertal advancement of the physical and reproductive systems and the attainment of characteristics considered sufficient to be classified as satisfactory potential-breeders [2]. A temporal limitation of the BSE involves the assessment of only the current status of physical, testicular and seminal characteristics; therefore, a satisfactory classification affords no implied guarantee of future reproductive performance of individual bulls [3].

Bulls from 12 to 24 months of age represent a progressive continuum of physical and sexual maturation and may be particularly vulnerable to factors that influence fertility. During natural service, the effects of extraneous influences on the fertility-associated parameters measured during a BSE, may contribute to alteration of reproductive capability and variability in reproductive performance [4]. Pregnancy rates achieved by bulls with satisfactory classification are consistently higher than untested bulls and generally higher than bulls not meeting satisfactory standards [5,6], however, the known limitations of the BSE [2,7] and the influence of environmental factors on fertility make the predictive value of the BSE towards reproductive performance of the individual bull unreliable $[6,8]$.

Yearling beef bulls would be expected to grow in physical stature and improve in reproductive function from 12 to 24 months of age [9-13]. Testicular development is expected to continue [11,13] and seminal quality, particularly spermatozoal form and viability, is expected to improve through this period $[4,11,14]$. The presumption would be that fertility should improve. Three components of the BSE, i.e., scrotal circumference, spermatozoal motility and spermatozoal morphology are inter-related and positively correlated and positive changes in these parameters through puberty are associated with fertility-potential $[15,16]$. Young bulls attaining satisfactory-classification on a prebreeding BSE would therefore presumptively be expected to advance in physical and reproductive capability. However, environmental and physiological stressors are known to unfavorably influence some physical and seminal characteristics [17-21]. Factors such as season, climatic temperatures, toxic principles, disease and injury, physiologic stress and nutritional imbalances have been linked with alterations in scrotal circumference and seminal quality $[17,22]$. The impacts appear to vary between individual bulls and generally 
are temporary, although occasionally they may precipitate permanent infertility of the bull [22]. Accordingly, the reproductive soundness of bulls following a BSE should be considered to be a dynamic condition, with both favorable and unfavorable potential changes.

Previous studies have investigated the variability in fertility and reproductive performance of yearling beef bulls under natural mating conditions. Variability in fertility of bulls with satisfactory potential-breeder classification on BSE has been reported $[8,23-$ 26]. Bulls of diverse genotypes have had differences in physical and reproductive traits from 12 to 18 months of age and general improvements in fertility-potential through this period [10,27,28]. Environmental conditions can influence the differences according to breed and age of the bull. However, limited study has evaluated the physical and reproductive changes young bulls undergo through a natural mating season and the subsequent effects on fertility during mating.

Yearling beef bulls in groups of two, exposed to natural mating for 3 days, and estrussynchronized mating for 1 day, were evaluated for the effect of mating load on fertility [23]. On post-exposure observations, the bulls had body weight losses of $25-26 \mathrm{~kg}$, with concurrent increases in scrotal circumference, however, seminal characteristics were not altered from pre-breeding BSE findings. In further work, mating performance of yearling beef bulls in groups of three were assessed with exposure to either natural or estrussynchronized mating for 44 days [24]. Although the bulls experienced BW losses of 30 $32 \mathrm{~kg}$, all bulls were classified as satisfactory on post-breeding BSE. An additional study evaluated yearling bulls of similar age, body weight, scrotal circumference and semen quality during single- and double-sire pasture matings [26]. After short, intense mating exposures and service capacity evaluations, post-breeding evaluations conducted 70-80 days following initial evaluations revealed normal increases in body weight and scrotal circumference, and no changes in seminal quality measurements. Mating activity levels did not influence physical or reproductive characteristics. Changes in physical condition of yearling bulls during mating have been confirmed, however, changes in testicular and seminal characteristics were not detected and variability in reproductive performance was not attributed to any alterations in reproductive capability.

To state that all yearling beef bulls with satisfactory classification on BSE are equally fertile throughout a mating season and will maintain reproductive soundness is tenuous and arguable. Realizing that fertility is an integration of multiple biological and behavioral components, the potential for deviation in the reproductive potential of the immature yearling bull affords possibilities for variability in performance. By observing and measuring the physical and reproductive characteristics of young beef bulls during a typical mating season, and the BSE-status at the completion of mating, knowledge regarding the potential changes in reproductive capability and subsequent variability in reproductive performance of bulls could be expanded. Furthermore, by monitoring environmental factors during mating and studying the associations of extraneous factors with the changes in physical and reproductive traits, additional information concerning the variance in reproductive performance of bulls could be provided. The objective of the study focuses on providing information applicable to explaining why all BSE-satisfactory yearling bulls do not perform equally in regards to reproductive outcomes during natural mating. 


\section{Materials and methods}

The observational study involved 74 crossbred yearling beef bulls, representing 7 Bos taurus sire-breed lines and either of two dam-breed lines, Hereford or Angus. The sirebreed lines (SBL) represented include: Angus, Charolais, Gelbvieh, Hereford, Limousin, Red Angus and Simmental. The bulls originated from a single beef cattle research operation and geographical location in south-central Nebraska, USA (U.S. MARC, USDAARS, Clay Center, NE, USA). The bulls were born in March and April of 2001, managed as a contemporary group following weaning (7-8 months of age) and through a traditional development period until the spring breeding season (June 2002). The bulls were defined as virgin yearling beef bulls at the initiation of the study (13-14 months of age). The females used for assessment of reproductive performance consisted of 2- and 3-year-old crossbred Bos taurus cows nursing spring-born calves $(n=581)$. The cows represented similar genetic compositions as the bulls and originated and were maintained as breeding populations of the research operation. Description of the female breeding populations and female fertility assessment has been previously reported [29].

Approximately 3 weeks prior to the breeding season, a Breeding Soundness Evaluation (BSE 1) was performed on all bulls, and repeated approximately 1 week prior to the breeding season on 14 individual bulls with deferred classification on the first exam. All BSE were performed and bulls classified according to the guidelines of the Society for Theriogenology [1]. Each bull was examined for soundness and health and individually identified. Examination of testicles, epdidymides, vesicle glands, ampullae, prostate and internal inguinal rings was accomplished by palpation and scrotal circumference was measured [30]. With the use of electroejaculation, the prepuce and penis were examined and semen samples were collected upon erection and ejaculation.

Semen samples were immediately evaluated for gross and progressive individual motility of spermatozoa under temperature-controlled conditions. Sperm morphology was assessed on eosin-nigrosin stained samples under phase contrast microscopy at $\times 1000$ and proportions of normal sperm were categorized on counts of 100 spermatozoa. Further classification of abnormal spermatozoa into defects of head, acrosome, midpiece and tail $[2,22]$ and evaluation for the presence of other abnormal seminal cells was performed. Classification of satisfactory potential-breeder was attained by achieving threshold measurements of: (1) $>30 \mathrm{~cm}$ scrotal circumference, (2) $>30 \%$ progressively motile spermatozoa, and (3) $>70 \%$ morphologically normal spermatozoa [2]. In addition, bulls were to be free of faults of physical and reproductive systems. For purposes of this study, all bulls not meeting satisfactory standards were categorized as unsatisfactory. Two trained veterinarians performed the evaluations and a trained veterinary technician and one trained veterinarian performed the semen evaluations.

From the bull population, individuals ( $n=57$, UFB) were randomly selected by the cattle operation to meet the sire-breed line requirements of pre-established genetic mating plans and by BSE-satisfactory classification. Random, stratified assignments by sire-breed line were made into six bull-groups (GRP) of nine or 10 bulls with GRP identification as A, B, C, D, E and F. Each GRP was assigned to one of three cowherds, designated as HRD1 $(n=194), 2(n=191)$ or $3(n=196)$, at a GRP bull-to-female ratio of $1: 20 \pm 2$ (mean + S.E.M.). Each HRD had two GRP of bulls rotated on 14-day intervals through a 
Table 1

Bull breeding-groups (GRP) and sire-breed line (SBL) distribution

\begin{tabular}{lllrlllllllll}
\hline GRP & HRD & R & \multicolumn{1}{c}{$n$} & AN & CH & GB & HH & LM & AR & SM & BSE 1 & Satis\% \\
\hline A & 1 & 1 & 9 & 1 & 1 & 2 & 1 & 1 & 2 & 1 & $9 / 9$ & 100 \\
B & 2 & 1 & 10 & 1 & 2 & 1 & 2 & 1 & 1 & 2 & $9 / 10$ & 90 \\
$\mathrm{C}^{\mathrm{a}}$ & 3 & 1 & 11 & 1 & 1 & 2 & $1+1^{\mathrm{a}}$ & 1 & $2+1^{\mathrm{a}}$ & 1 & $11 / 11$ & 100 \\
$\mathrm{D}$ & 1 & 2 & 10 & 1 & 2 & 1 & 2 & 1 & 1 & 2 & $10 / 10$ & 100 \\
$\mathrm{E}$ & 2 & 2 & 9 & 1 & 1 & 2 & 1 & 1 & 2 & 1 & $9 / 9$ & 100 \\
$\mathrm{~F}^{\mathrm{a}}$ & 3 & 2 & 11 & 1 & 2 & 1 & 2 & 1 & 1 & $2+1^{\mathrm{a}}$ & $11 / 11$ & 100 \\
UFB & & & 60 & 6 & 9 & 9 & 10 & 6 & 10 & 10 & $59 / 60$ & 98 \\
NUB & & & 14 & 3 & 7 & 1 & 1 & 0 & 0 & 2 & $8 / 14$ & 57 \\
All bulls & & & 74 & & & & & & & & $67 / 74$ & 90.5 \\
\hline
\end{tabular}

BSE 1 classification Herd and rotation assignments. GRP, bull-group; HRD, breeding herd; R, breeding rotation; Satis\%, BSE satisfactory potential breeder classification.

a Replacement bulls for injured bulls removed early during breeding season.

standard 63-day mating season (early June to mid-August), thus each GRP had two distinct mating periods. Bull-groups A, B, and C in rotation 1 (R1) were exposed to females for 28 total days with a 14-day rest period, whereas bull-groups D, E, and F in rotation 2 (R2) were exposed to females for 35 total days with a 14-day rest period (Table 1). During the first mating periods for GRP C and F, 3 bulls were removed and replaced with like sire-breed bulls, therefore 60 UFB bulls were exposed to mating. The remaining bulls $(n=14, \mathrm{NUB})$ were maintained on grass pastures without mating exposure during the same time period. Mating pasture environments during the season varied between HRD and R, from native cool-season grasses, irrigated grasses and forages, and irrigated alfalfa, due to the extended low precipitation and higher than normal climatic temperatures for the season.

On Day 1 of each GRP mating period, bulls were individually weighed (non-shrunk BW), body condition score (BCS) estimated, hip height $(\mathrm{HH})$ measured and scrotal circumference (SC) measured. Additionally, inspection for physical soundness was performed. Within 96-h following the last day of mating exposure for each GRP, the remaining UFB bulls ( $n=57)$ were subjected to a BSE (BSE 2$)$ and final BW, BCS, HH and SC were measured. BSE 2 was performed the same as previously outlined. The NUB bulls $(n=13)$ were similarly evaluated at the completion of the study.

The bulls were individually monitored by GRP throughout the mating season for aberrations of physical and reproductive soundness, i.e., injuries and illness. Injuries were diagnosed and categorized as musculoskeletal or reproductive by field observation and severity, duration, and prognosis determined the continuation or removal from mating exposure. A cumulative injury score was assigned as 1-point per injury incident and 3points for removal from the mating pasture for each individual bull and the date of each injury incident plotted on a mating season time line.

Average daily climatic temperatures and daily peak temperatures, along with average relative humidity and precipitation were collected from the National Weather Service regional reporting center in Hastings, NE, USA.

Approximately 65 days following the completion of the mating season, the three HRD were palpated per rectum for pregnancy status and further definition of bull reproductive performance was assessed with calving dates and calving distributions of the females. A 
283-day average gestation length was utilized to estimate date of conception from calving dates.

Variables amendable to analysis of variance were subjected to a statistical software program, ANOVA-single factor test [31]. Further analysis of covariance, simple and rank correlation, and simple linear regression were performed to measure association and relationships [31]. All procedures were assessed at 0.05 critical values for the $F$-statistic. Least square means and standard errors of the mean (S.E.M.) are reported for data sets and sample comparisons. Variables with non-normal distributions and heterogeneous variances were converted to categorical data where appropriate and Chi square tests of independence and trend analysis were performed. Wilcoxon-Mann-Whitney nonparametric tests were used to compare distributions of ordinal-scale variables and Kruskal-Wallis H tests were utilized to determine significant differences of rank-transformed sample means of semen quality statistics. The software program PEPI, Version 4.0x [32] was utilized to perform nonparametric analyses. Limitations were assumed with sample groups of small and unequal sizes, such as GRP and SBL, however, mean and S.E.M. values for the variables are reported and conservative analysis of trends and variance procedures (Tukey's Studentized Range Test) were utilized.

\section{Results}

\subsection{Pre-breeding observations}

The BSE 1 was performed 17 and 31 days prior to the initiation of the breeding season for mating rotations R1 and R2, respectively. Final satisfactory classification was given to 67 of the 74 bulls $(90.5 \%)$. To meet the sire-breed requirements for each GRP, one Limousin-sired bull with unsatisfactory classification was selected as a UFB candidate, therefore, 59 of the 60 UFB bulls $(98 \%)$ began the breeding season with satisfactory potential-breeder classification. This individual was assigned to GRP B in R1; bull B6. For the NUB bulls, 8 of $14(57 \%)$ were classified as satisfactory potential-breeders.

Age of the 74 crossbred yearling beef bulls at BSE 1 was $428 \pm 0.8$ days (mean \pm S.E.M.) with a range of 28 days (414-442 days of age) -approximately 13.5-14.5 months of age. No differences in age were revealed between any of the bull sample-groups or sire-breed groups $(P>0.10)$. No significant correlations were demonstrated for age at BSE 1 with other BSE observations or physical characteristics.

Scrotal circumference (SC) for all bulls was $36.3 \pm 0.2 \mathrm{~cm}$ (range, $32.5-45.0 \mathrm{~cm}$ ). All bulls exceeded the minimum required SC of $30 \mathrm{~cm}$ for bulls $12-15$ months of age. No differences in SC were revealed between any of the bull sample-groups or sire-breed groups $(P>0.10)$ or between bulls classified as satisfactory or unsatisfactory. Examination of testicles and epididymides revealed no gross abnormalities, except for bull B6 (GRP B) who was detected to have unequal testicle size due to one testicle being smaller and softer in tone. No association of age with SC was revealed $(P>0.10)$.

Progressive, individual spermatozoal motility (MOT\%) for all bulls was $57.8 \pm 1.6 \%$ (range, 25-80\%). All UFB bulls exceeded the $>30 \%$ threshold for progressive motility and 49 of $60(82 \%)$ had motility percentages greater than $50 \%$. Four NUB bulls had MOT\% 
$<30 \%$ and 9 of $14(64 \%)$ had motility $>50 \%$. No differences in spermatozoal motility were detected between bull sample-groups or sire-breed groups $(P>0.10)$. MOT\% was not significantly associated with SC or age although a negative correlation was demonstrated with primary abnormal sperm (PRM\%), $r=-0.28(P<0.05)$ and secondary abnormal sperm (SEC\%), $r=-0.33(P<0.05)$. Bulls classified as unsatisfactory potential-breeders $(n=7)$ had a lower MOT\% than the satisfactory bulls, $38.4 \%$ compared to $59.9 \%$, $(P<0.05)$.

Evaluation for morphological characteristics revealed the percentage of normal spermatozoa (MRPH\%) was $80.4 \pm 1.5 \%$ for all bulls. The range of distribution for normal spermatozoa was 28-96\%. All UFB bulls, except bull B6 (28\% normal sperm), exceeded the $>70 \%$ threshold for morphologically normal spermatozoa. Nine of 14 NUB bulls $(64 \%)$ had $>70 \%$ MRPH $\%$. There were no differences revealed in percentage of normal morphology for any of the bull sample-groups or sire-breed groups $(P>0.10)$. Bulls classified as unsatisfactory potential-breeders $(n=7)$ had lower percentages of morphologically normal spermatozoa, $52.3 \pm 8.5 \%$, than bulls classified as satisfactory $(n=67), 83.3 \pm 0.9 \%(P<0.05)$. MRPH\% was weakly and negatively correlated to SC, $r=-0.20(P=0.08)$ and positively correlated to MOT\%, $r=0.37(P<0.01)$.

Spermatozoa with abnormal morphological features were classified according to defect-type and were categorized as primary (PRM\%) or secondary abnormalities (SEC\%). Overall, the percentage of primary abnormal spermatozoa was $13.3 \pm 1.8 \%$, which included specific abnormalities of the spermatozoal head, acrosome, midpiece and/ or the presence of proximal protoplasmic droplets. The range of distribution for primary abnormal sperm was $2-54 \%$. The bulls classified as unsatisfactory had higher percentages of primary abnormal spermatozoa, $29.1 \%$ compared to $12.1 \%(P<0.01)$ for the bulls classified as satisfactory $(P<0.05)$. The percentage of secondary abnormal spermatozoa was $6.3 \pm 0.7 \%$ (range, $0-37 \%$ ). Defects categorized as secondary included specific tail abnormalities, normal-appearing detached sperm heads, and distal protoplasmic droplets. The bulls classified as unsatisfactory had higher percentages of secondary abnormal sperm than the satisfactory bulls $(P<0.01)$, 18.6 versus $4.5 \%$, respectively No differences in primary or secondary morphologically abnormal spermatozoa were revealed between UFB bull sample-groups or sire-breed groups $(P>0.10)$. The LM sirebreed group had numerically higher PRM\% $(21.2 \pm 6.8 \%)$ due to the inclusion of bull B6 with $54 \%$ primary abnormal spermatozoa. No differences in specific classes of morphology defects (primary or secondary) were detected between sample-groups $(P>0.10)$. Midpiece defects $(5.2 \%)$, detached, normal sperm heads $(3.6 \%)$ and proximal protoplasmic droplets $(3.6 \%)$ were numerically the most prevalent for bulls classified as satisfactory. No significant correlations were demonstrated for PRM\% with SC and age. However, SEC\% was positively associated with SC, $r=0.26(P<0.05)$; refer to Tables 2 and 3 for BSE 1 results.

Physical and reproductive examination of the bulls revealed several individuals with abnormalities. Abnormalities (enlargement, increased tone, tenderness) of the vesicular glands (seminal vesiculitis) were detected by palpation in three NUB bulls with concomitant white blood cells in the semen. A bull with an injured foot and one bull with a persistent penile frenulum were placed in the NUB group and one bull, which failed to adequately extend the penis during electroejaculation, was also placed as a NUB. 
Table 2

Reproductive characteristics

\begin{tabular}{|c|c|c|c|c|c|c|c|}
\hline & \multirow[t]{2}{*}{$n$} & \multicolumn{6}{|c|}{ Least square means (S.E.M.) for bull population and sample groups } \\
\hline & & $\begin{array}{l}\text { Age BSE } \\
\text { (days) }\end{array}$ & $\begin{array}{l}\text { SC BSE } \\
(\mathrm{cm})\end{array}$ & $\begin{array}{l}\text { MOT\% } \\
\text { (\%live) }\end{array}$ & $\begin{array}{l}\text { MRPH\% } \\
\text { (\% normal) }\end{array}$ & $\begin{array}{l}\text { PRM\% } \\
\text { (\% primary) }\end{array}$ & $\begin{array}{l}\text { Satis } \% \\
\text { (satisfactory) }\end{array}$ \\
\hline \multicolumn{8}{|l|}{ BSE 1} \\
\hline All Bulls & 74 & $428(0.8)$ & $36.3(0.2)$ & $57.8(1.6)$ & $80.4(1.5)$ & $13.3(1.8)$ & 90.50 \\
\hline UFB & 60 & $428(0.9)$ & $36.5(0.3)$ & $59.4(1.7)$ & $81.8(1.3)$ & $13.5(1.1)$ & 98 \\
\hline NUB & 14 & $430(1.6)$ & $36.2(0.6)$ & $51.0(4.4)$ & $74.4(5.7)$ & $14.7(3.1)$ & 57 \\
\hline Herd 1 & 19 & $429(2.0)$ & $35.9(0.4)$ & $56.3(3.3)$ & $84.2(1.3)$ & $10.6(1.6)$ & 100 \\
\hline Herd 2 & 19 & $428(2.0)$ & $36.9(0.4)$ & $60.5(3.3)$ & $80.6(3.2)$ & $14.4(2.8)$ & 95 \\
\hline Herd 3 & 22 & $427(1.0)$ & $36.3(0.6)$ & $61.1(2.3)$ & $80.8(2.0)$ & $15.0(2.3)$ & 100 \\
\hline $\mathrm{R} 1-\mathrm{ABC}$ & 30 & $427(1.3)$ & $36.6(0.4)$ & $55.8(2.5)$ & $81.1(2.2)$ & $14.4(2.8)$ & 97 \\
\hline $\mathrm{R} 2-\mathrm{DEF}$ & 30 & $428(1.1)$ & $36.1(0.3)$ & $63.0(2.0)$ & $82.4(1.4)$ & $12.6(1.7)$ & 100 \\
\hline \multicolumn{8}{|c|}{ GRP (UFB only) } \\
\hline A & 9 & 428 & $35.7(0.5)$ & $51.1(5.1)$ & $85.7(1.2)$ & $9.6(1.4)$ & 100 \\
\hline $\mathrm{B}$ & 10 & 428 & $37.3(0.6)$ & $58.0(4.4)$ & $76.6(5.8)$ & $17.3(4.4)$ & 90 \\
\hline $\mathrm{C}$ & 11 & 426 & $36.7(0.9)$ & $57.7(3.8)$ & $81.5(2.7)$ & $15.2(2.0)$ & 100 \\
\hline $\mathrm{D}$ & 10 & 430 & $36.1(0.6)$ & $61.0(3.8)$ & $82.8(2.1)$ & $11.7(1.7)$ & 100 \\
\hline $\mathrm{E}$ & 9 & 428 & $36.4(0.5)$ & $63.3(5.0)$ & $85.0(1.5)$ & $10.8(1.3)$ & 100 \\
\hline $\mathrm{F}$ & 11 & 428 & $35.9(0.6)$ & $64.5(2.1)$ & $80.0(3.2)$ & $14.9(2.6)$ & 100 \\
\hline \multicolumn{8}{|c|}{ SBL (UFB only) } \\
\hline \#1-AN & 6 & 433 & $36.4(2.6)$ & $68.3(1.7)$ & $86.7(2.4)$ & $7.7(1.0)$ & 100 \\
\hline$\# 2-\mathrm{CH}$ & 9 & 434 & $35.4(0.6)$ & $55.5(5.4)$ & 84.4 (1.9) & $11.3(1.0)$ & 100 \\
\hline$\# 3-\mathrm{GB}$ & 9 & 427 & $36.9(0.5)$ & $56.7(5.5)$ & $83.3(2.6)$ & $12.6(2.7)$ & 100 \\
\hline \#4-HH & 10 & 426 & $37.2(1.0)$ & $67.0(2.6)$ & $79.3(2.2)$ & $16.2(1.7)$ & 100 \\
\hline \#5-LM & 6 & 425 & $35.8(0.5)$ & $54.2(7.6)$ & $73.2(9.3)$ & $21.2(6.8)$ & 83 \\
\hline \#6-AR & 10 & 426 & $35.5(0.5)$ & $54.0(3.1)$ & $81.4(2.4)$ & $12.8(2.0)$ & 100 \\
\hline$\# 7-\mathrm{SM}$ & 10 & 425 & $37.1(0.6)$ & $61.0(3.1)$ & 82.9 (3.2) & $13.1(2.7)$ & 100 \\
\hline Range & & $414-442$ & $32.5-45.0$ & $25-80$ & $28-96$ & $2-54$ & \\
\hline
\end{tabular}

BSE 1: breeding soundness evaluation.

Analysis of least square means via ANOVA-single factor test, Kruskal-Wallis test.

Analysis of rates and proportions via Chi square; trend analysis, multiple comparisons.

Rows with different letters are different $(P<0.05$ or less).

At the beginning of the breeding season, the non-shrunk BW of the UFB bulls was $549 \pm 6 \mathrm{~kg}$, BCS was estimated at 6.1, and hip height averaged $52.1 \mathrm{in}$. For the NUB bulls, BW was interpolated at $555 \mathrm{~kg}$, BCS was estimated at 6.1 and hip height averaged $52.6 \mathrm{in}$. No differences were revealed between UFB sample-groups or sire-breed groups $(P>0.10)$ or between bulls classified satisfactory or unsatisfactory. BW was positively correlated with BCS ( $r=0.41, P<0.001)$, HH $(r=0.61, P<0.001)$, and SC $(r=0.46, P<0.001)$; refer to Table 4.

Scrotal circumference, re-measured just prior to the first mating exposures for all UFB bulls, was $35.9 \pm 0.3 \mathrm{~cm}$, with a range from 32.0 to $44.0 \mathrm{~cm}$. No differences were demonstrated between bull sample-groups or sire-breed groups $(P>0.10)$. SC just prior to mating was $0.6 \mathrm{~cm}$ less than the SC measured at BSE 1, corresponding to a time period of 
Table 3

Reproductive characteristics for BSE 1: UFB bulls

\begin{tabular}{llll}
\hline BSE variables & \multicolumn{2}{l}{ Least square means and S.E.M. } & \\
\cline { 2 - 4 } & BSE 1 satisfactory & BSE 1 unsatisfactory & BSE 1 UFB bulls \\
\hline$n$ & 67 & 7 & 60 \\
Age (days) & $428(0.8)$ & $429(1.5)$ & $428(0.9)$ \\
SC (cm) & $36.2(0.3)$ & $37.1(0.8)$ & $36.5(0.3)$ \\
MOT\% & $59.9(1.5) \mathrm{a}$ & $38.4(4.5) \mathrm{b}$ & $59.4(1.7)$ \\
MRPH\% & $83.3(0.9) \mathrm{a}$ & $52.3(8.5) \mathrm{b}$ & $81.8(1.3)$ \\
PRM\% (primary) & $12.1(0.8) \mathrm{a}$ & $29.1(8.3) \mathrm{b}$ & $13.5(1.1)$ \\
SEC\% (secondary) & $4.5(0.4) \mathrm{a}$ & $18.6(4.7) \mathrm{b}$ & $4.7(1)$ \\
Head defects $(\%)$ & 3.3 & 4.1 & 3.3 \\
Midpiece defects $(\%)$ & 5.2 & 8.9 & 5.2 \\
Tail defects $(\%)$ & $1.0 \mathrm{a}$ & $5.6 \mathrm{~b}$ & 1.0 \\
Detached heads $(\%)$ & $3.6 \mathrm{a}$ & $14.7 \mathrm{~b}$ & 3.6 \\
Prox. droplets $(\%)$ & $3.6 \mathrm{a}$ & $13.0 \mathrm{~b}$ & 3.6 \\
Acrosome defects $(\%)$ & 0.8 & 1.1 & 0.8 \\
Nuclear defects $(\%)$ & 0.2 & 0.7 & 0.7 \\
\hline
\end{tabular}

Comparison of satisfactory and unsatisfactory bulls. Analysis of least square means and variances via ANOVAsingle factor test. Columns with different letters $(\mathrm{a}$ and $\mathrm{b})$ are different $(P<0.05)$. Classification of primary (PRM\%) and secondary (SEC\%) spermatozoal abnormalities and specific classification of spermatozoal defects according to reference sources [2,22].

17-31 days. Thirty-two UFB bulls (53\%) had declines in SC from 0.5 to $2.5 \mathrm{~cm}, 13 \mathrm{UFB}$ bulls (22\%) had increases in SC from 0.5 to $2.0 \mathrm{~cm}$, and 15 UFB bulls $(25 \%)$ had no change in SC. Overall, the change in SC for UFB bulls represented a $1.67 \%$ decline in SC. No differences were revealed for percentage-change of SC between UFB sample-groups or sire-breed groups $(P>0.05)$; refer to Table 4 .

SC was positively correlated with starting BW, $r=0.46(P<0.001)$, BCS, $r=0.27$ $(P<0.05)$, and hip height, $r=0.38(P<0.001)$. In addition, SC was positively correlated with MOT\% from BSE $1, r=0.22(P=0.08)$ although revealing a weak trend for negative correlation with MRPH\%, $r=-0.12(P=0.25)$.

Physical inspection of the UFB bulls just prior to the first mating exposures revealed no detectable abnormalities or injuries.

Table 4

Pre-breeding physical characteristics for bull population and sample groups

\begin{tabular}{lllllllll}
\hline \multicolumn{7}{c}{ Least square means and S.E.M. } \\
\cline { 2 - 8 } & UFB & NUB & Herd 1 & Herd 2 & Herd 3 & R1 (ABC) & R2 (DEF) & Range \\
\hline$n$ & 60 & 14 & 19 & 19 & 22 & 30 & 30 & 60 \\
Age (days) & $454(1)$ & & $453(3)$ & $454(2)$ & $455(2)$ & $446(1)$ & $461(1)$ & 431 to 473 \\
BW (kg) & $549(6)$ & $555^{\text {a }}$ & $534(10)$ & $558(12)$ & $554(9)$ & $553(10)$ & $545(8)$ & 445 to 643 \\
Hip ht. (in) & $52.1(0.1)$ & 52.6 & $51.6(0.3)$ & $52.3(0.3)$ & $51.9(0.3)$ & $52.1(0.3)$ & $51.8(0.3)$ & 48.0 to 54.5 \\
BCS & $6.11(0.1)$ & 6.10 & $6.11(0.1)$ & $6.10(0.1)$ & $6.16(0.1)$ & $6.11(0.1)$ & $6.12(0.1)$ & 5.5 to 7.0 \\
SC (cm) & $35.9(0.3)$ & & $35.2(0.4)$ & $36.2(0.3)$ & $36.1(0.5)$ & $35.9(0.4)$ & $35.8(0.3)$ & 32.0 to 44.0 \\
SC chg (cm) & $0.6(0.13)$ & & 0.7 & 0.7 & 0.2 & 0.7 & 0.4 & 2.0 to -2.5 \\
SC chg (\%) & -1.67 & & -1.99 & -1.93 & -0.55 & -1.95 & -0.84 & 5.8 to -6.9 \\
\hline
\end{tabular}

\footnotetext{
${ }^{\text {a }} \mathrm{BW}$ interpolated from ave.-daily-gain from yearling BW of UFB bulls.
} 


\subsection{Post-breeding observations}

Within 3 days following removal of each GRP from their respective HRD, a Breeding Soundness Evaluation (BSE 2) was performed on the remaining UFB bulls $(n=57)$. The elapsed time between BSE 1 and BSE 2 was an average of 72 days for the UFB bulls, and ranged from 61 to 87 days by GRP. R1 averaged 64 days and R2 averaged 84 days, the difference between $\mathrm{R}$ corresponding to the 21-day duration of the last mating period. The NUB bulls were similarly subjected to a follow-up BSE on Day 67 following BSE 1.

The SC for the UFB bulls was $34.9 \pm 0.2 \mathrm{~cm}$, a $2.87 \%$ decline from the SC of $35.9 \pm 0.3 \mathrm{~cm}$ at the start of the breeding season and an overall decline of $4.58 \%$ from the $36.5 \pm 0.3 \mathrm{~cm} \mathrm{SC}$ at BSE $1(P<0.01$; Fig. 1$)$. The range of percentage of decline for 54 UFB bulls was $0-12.5 \%(4.0 \mathrm{~cm})$ with 3 UFB bulls having SC increases up to $2.9 \%$ $(1.0 \mathrm{~cm})$. The range of SC measurements was 31.0-41.0 cm. Conversely, 12 NUB bulls had an increase in SC from BSE 1 to BSE 2 of $2.49 \%, 36.2 \pm 0.6$ to $37.1 \pm 0.6 \mathrm{~cm}$ respectively, with one individual declining in SC and one bull diagnosed with orchitis. The decline in SC for UFB bulls was decidedly different than the increase of SC for NUB bulls $(P<0.001$; Table 5).

The SC at the end of breeding was strongly correlated to SC at the start of breeding $(r=0.79, P<0.01)$. The percentage-change in SC from BSE 1 to BSE 2 was positively correlated to SC at BSE $1(r=0.39, P=0.01)$ with bulls having SC greater than $36 \mathrm{~cm}$ at BSE 1 more likely to have negative and greater SC changes $(P<0.05)$. The change in SC was weakly associated with BW loss during the first mating period $(r=0.22, P=0.11)$ and modestly associated with BW loss during the second mating period $(r=0.35, P=0.05)$ and with total BW loss $(r=0.24, P=0.07)$. No differences in change of SC or mean SC at the end of breeding were demonstrated between UFB sample-groups or sire-breed groups $(P>0.10)$. The change in SC measured during BSE 2 revealed no significant relationships with R, HRD, GRP or SBL $(P>0.10)$. The change in SC at BSE 2 had minimal and weak associations with semen quality parameters. Rank correlation with MOT\% was $r=0.13$ $(P>0.10)$ and with MRPH\% was $r=0.10(P>0.10)$. No association was detected with $\mathrm{PRM} \%$ or SEC\%.

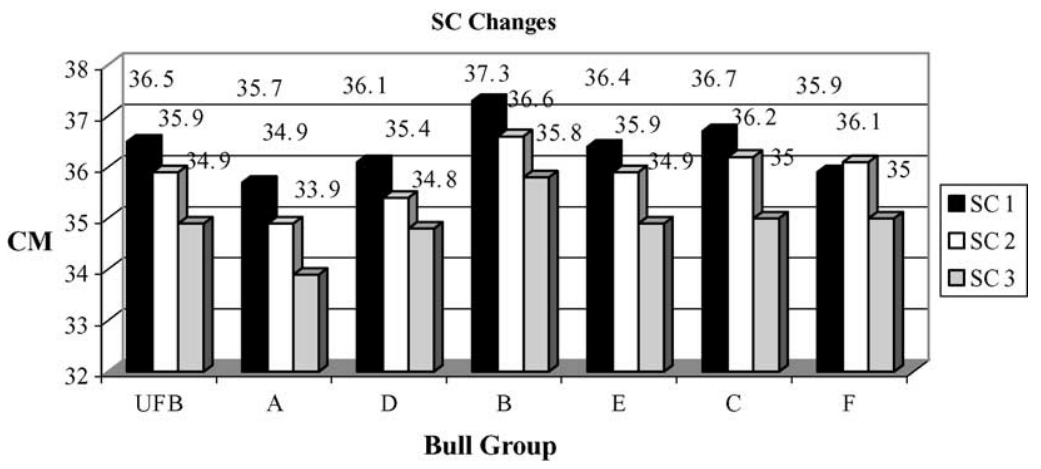

Fig. 1. SC Changes from BSE 1, to start of breeding, to BSE 2. SC1 - scrotal circumference at BSE 1, SC2 scrotal circumference at start of breeding season, SC3—scrotal circumference at BSE 2. 
Table 5

Reproductive characteristics of bulls

\begin{tabular}{|c|c|c|c|c|c|c|c|}
\hline$n$ & $\begin{array}{l}\text { Time } \\
\text { (days) }\end{array}$ & $\begin{array}{l}\text { MOT\% } \\
\text { (\%live) }\end{array}$ & $\begin{array}{l}\text { MRPH\% } \\
\text { (\%normal) }\end{array}$ & $\begin{array}{l}\text { PRM\% } \\
\text { (\%primary) }\end{array}$ & $\begin{array}{l}\text { SEC\% } \\
\text { (\%second) }\end{array}$ & $\begin{array}{l}\text { Satis\% } \\
\text { (satisfactory) }\end{array}$ & $\begin{array}{l}\text { SC BSE } 2 \\
(\mathrm{~cm})\end{array}$ \\
\hline
\end{tabular}

\begin{tabular}{|c|c|c|c|c|c|c|c|c|}
\hline \multicolumn{9}{|l|}{ BSE 2 results } \\
\hline All bulls & 70 & 72 & $52.7(2.5)$ & $63.0(3.1)$ & $23.8(2)$ & $13.2(1.5)$ & 58.60 & $35.4(0.2)$ \\
\hline UFB & 57 & 73 & $54.5(2.5)$ & $65.2(3.2)$ & $24.7(2.4)$ & $9.7(1.6)$ & $63.00 \mathrm{a}$ & 34.9 a $(0.2)$ \\
\hline NUB & 13 & 67 & $48.9(6.5)$ & $51.3(8.2)$ & $21.7(4.4)$ & $23.0(6.0)$ & $36.00 \mathrm{~b}$ & $37.1 \mathrm{~b}(0.6)$ \\
\hline Herd 1 & 17 & 72 & $57.6(6)$ & $70.2(4)$ & $19.9(4)$ & $9.8(3.1)$ & 76.00 & 35.9 a $(0.4)$ \\
\hline Herd 2 & 19 & 74 & $59.5(4)$ & $66.7(8)$ & $24.5(6)$ & $8.8(2.4)$ & 63.00 & $36.9 \mathrm{ab}(0.4)$ \\
\hline Herd 3 & 21 & 76 & $47.4(7)$ & $60.9(7)$ & $28.8(5)$ & $10.3(2.9)$ & 52.00 & $36.3 \mathrm{~b}(0.6)$ \\
\hline $\mathrm{R} 1-\mathrm{ABC}$ & 30 & 64 & 52.7 (3.9) & $61.1(4.8)$ & $26.4(5)$ & $12.4(2.7)$ & 57.00 & 35.0 a $(0.4)$ \\
\hline $\mathrm{R} 2-\mathrm{DEF}$ & 27 & 84 & $56.5(3.3)$ & $70.6(3.9)$ & $22.7(5)$ & $6.6(1.3)$ & 70.00 & $34.9 \mathrm{~b}(0.3)$ \\
\hline \multicolumn{9}{|c|}{ GRP (UFB only) } \\
\hline A & 9 & 61 & $55.6(6)$ & $59.9(10)$ & 26.5 a $(7)$ & $13.6 \mathrm{ab}(6)$ & $56.00 \mathrm{a}$ & $33.9 \mathrm{ab}(0.5)$ \\
\hline B & 10 & 63 & $60.0(4)$ & $69.9(7)$ & $20.6 \mathrm{ab}(5)$ & $9.5 \mathrm{ab}(4)$ & $70.00 \mathrm{ab}$ & $35.8 \mathrm{~b}(0.5)$ \\
\hline $\mathrm{C}$ & 11 & 66 & $43.6(8)$ & $54.2(9)$ & 31.6 a $(6)$ & 14.2 a (3) & $46.00 \mathrm{a}$ & 35.0 a $(0.8)$ \\
\hline $\mathrm{D}$ & 8 & 82 & $60.0(7)$ & $82.1(2)$ & $12.5 \mathrm{~b} \mathrm{(2)}$ & $5.4 \mathrm{~b}(1)$ & $100.00 \mathrm{~b}$ & 34.8 c $(0.5)$ \\
\hline $\mathrm{E}$ & 9 & 84 & 58.9 (4) & $63.1(9)$ & $28.7 \mathrm{ab}(8)$ & $8.1 \mathrm{ab}(3)$ & $56.00 \mathrm{ab}$ & $34.9 \mathrm{ab}(0.3)$ \\
\hline $\mathrm{F}$ & 10 & 87 & $51.5(6)$ & $68.2(6)$ & $25.7 \mathrm{ab}(5)$ & $6.1 \mathrm{ab}(4)$ & $60.00 \mathrm{~b}$ & $35.0 \mathrm{ab}(0.6)$ \\
\hline \multicolumn{9}{|c|}{ SBL (UFB only) } \\
\hline \#1-AN & 6 & & 43.3 & 46.3 & $38.3 \mathrm{a}$ & $15.4 \mathrm{a}$ & $50.00 \mathrm{a}$ & 36.4 a (2.6) \\
\hline$\# 2-\mathrm{CH}$ & 9 & & 54.4 & 72.6 & $19.9 \mathrm{~b}$ & $7.5 \mathrm{~b}$ & $78.00 \mathrm{ab}$ & $35.4 \mathrm{~b}(0.6)$ \\
\hline$\# 3-\mathrm{GB}$ & 9 & & 56.7 & 75.0 & $19.3 \mathrm{~b}$ & $5.7 \mathrm{~b}$ & $78.00 \mathrm{~b}$ & $36.9 \mathrm{~b}(0.5)$ \\
\hline \#4- $\mathrm{HH}$ & 9 & & 46.1 & 59.3 & $27.9 \mathrm{ab}$ & $12.8 \mathrm{ab}$ & $44.00 \mathrm{ab}$ & 37.2 a (1.0) \\
\hline \#5-LM & 6 & & 50.0 & 55.0 & $25.2 \mathrm{ab}$ & $19.8 \mathrm{ab}$ & $50.00 \mathrm{a}$ & 35.8 a $(0.5)$ \\
\hline$\# 6-\mathrm{AR}$ & 9 & & 58.9 & 69.3 & $23.4 \mathrm{ab}$ & $7.3 \mathrm{ab}$ & $67.00 \mathrm{ab}$ & $35.5 \mathrm{~b}(0.5)$ \\
\hline \#7-SM & 9 & & 66.7 & 71.9 & $25.6 \mathrm{~b}$ & $2.5 \mathrm{ab}$ & $67.00 \mathrm{~b}$ & $37.1 \mathrm{~b}(0.6)$ \\
\hline Range (\%) & & & $0-80$ & 0-94 & $3-87$ & $0-82$ & & $31.0-41.0$ \\
\hline
\end{tabular}

Breeding soundness evaluation (BSE 2).

Analysis of least square means and variance via ANOVA-single factor test.

Analysis of rates and proportions via Chi square test of association; trend analysis, multiple comparisons.

Columns with different letters $(\mathrm{a}$ and $\mathrm{b})$ are different $(\mathrm{P}<0.05$ or less).

Time = days between BSE 1 and BSE 2 .

Estimation of progressive individual spermatozoal motility (MOT\%) for the UFB bulls was $54.5 \pm 2.5 \%$ and for the NUB bulls was $48.9 \pm 6.5 \%(P>0.10)$. MOT\% for BSE 2 was not different than MOT\% for BSE $1(P>0.10)$, for either UFB or NUB bulls. Individually, 56\% $(n=32)$ of the UFB had increases in MOT\% and $44 \%(n=25)$ had declines. The range of MOT\% was $0-80 \%$ progressively motile sperm. No differences were detected between R, HRD, GRP or SBL $(P>0.10)$; refer to Tables 5 and 6 . MOT\% was associated with BSE 2 classification $(P<0.01)$ as 16 of the 21 bulls classified as unsatisfactory had motility percentages less than $30 \%$ and 14 of 25 UFB bulls with MOT\% declines were classified as unsatisfactory. UFB bulls classified as unsatisfactory $(n=21)$ 
had MOT\% of $40.4 \%$ compared to the $62.8 \%$ for the bulls classified as satisfactory $(P<0.01)$. No association was revealed between SC at the end of the breeding season and MOT\%, and no correlation between the change in SC from BSE 1 to BSE 2 with MOT\% was revealed, $r=0.13(P>0.10)$. A strong, positive correlation of MOT\% with MRPH\% existed $(r=0.55, P<0.01)$, indicating that as motility percentage decreased, percentage of morphologically normal spermatozoa decreased. MOT\% on BSE 2 demonstrated no significant associations with body weight losses or with injury scores $(P>0.10)$.

Percentage of normal spermatozoa (MRPH\%) declined from $80.4 \pm 1.5 \%$ on BSE 1 to $63.0 \pm 3.1 \%$ for the 70 bulls completing BSE $2(P<0.01)$. For both the UFB and NUB bulls, MRPH\% declined 7-32\% for all bull-groups, with the single exception of GRP D, whose 8 remaining bulls maintained a high percentage of normal spermatozoa on both evaluations (82\%). MRPH\% declined for the UFB bulls from 81.8 to $65.2 \%(P<0.05)$ and for the NUB bulls from 74.4 to $51.3 \%(P<0.05)$. The declines in MRPH\% were not different between UFB and NUB $(P>0.10)$. Individually, 18 UFB bulls had increased MRPH\% and 39 had declines $(P<0.01)$. The range of MRPH\% was from 0 to $94 \%$ morphologically normal spermatozoa. No differences in MRPH\% or the level of decline of MRPH from BSE 1 to BSE 2 were demonstrated for R or HRD; however, GRP and SBL differences in MRPH\% were evident $(P<0.05)$. GRP A and $\mathrm{C}$ demonstrated lower percentages of normal spermatozoa $(54-59 \%)$ than the other GRP, particularly in comparison to GRP D (82\%), and the AN- $(46 \%)$ and the LM-SBL $(55 \%)$ had considerably reduced MRPH\% than the other SBL $(P<0.05)$; refer to Tables 5 and 6 . The degree of change in sperm morphology was influential on BSE 2 classification, as bulls with improved MRPH\% $(n=19)$ or low levels of declines $(n=10)$ were highly likely (8.7 to 1$)$ to be classified as satisfactory, whereas bulls with greater than $10 \%$ declines $(n=28)$ were 1.8 -times more likely to be classified as unsatisfactory $(P<0.001)$. The AN-SBL revealed a $40 \%$ decline in MRPH\% overall which resulted in 50\% of this SBL being classified as unsatisfactory. Bulls classified as satisfactory had MRPH\% of $80.6 \pm 1 \%$ compared to $40.0 \pm 5 \%$ for the bulls classified as unsatisfactory $(P<0.01)$.

The percentage of primary abnormal spermatozoa (PRM\%) increased from levels revealed at BSE 1, $23.8 \pm 2 \%$ compared to $13.3+2 \%$, respectively $(P<0.01)$. Increases of PRM\% were larger for the UFB bulls (11.2\% increase) compared to the NUB (7\% increase). Differences in PRM\% were demonstrated between GRP and SBL, with GRP C $(31.6 \%)$ and the AN-SBL (38.3\%) having higher PRM\% than the other groups $(P<0.05)$; refer to Fig. 2. Differences in PRM\% were not demonstrated for R or HRD, although HRD3 had a trend for higher primary abnormal spermatozoa $(P=0.09)$. R1 had numerically more PRM\% than R2 $(P=0.12)$. All classes of primary abnormal defects increased from BSE 1 , with proximal protoplasmic droplets, abnormal head shape and nuclear defects (diadem craters) being the predominant and most significant increases $(P<0.05)$. The bulls classified as unsatisfactory had nearly double the levels of acrosome, abnormal head shape and midpiece defects, 5-times more protoplasmic droplets and nearly 10-times the percentages of nuclei with diadem craters $(9.8$ versus $1.0 \%)$ than the satisfactory bulls $(P<0.05)$; refer to Table 6.

Secondary spermatozoal abnormalities (SEC\%) increased at BSE 2 to $13.2 \pm 1.5 \%$ for all bulls, compared to $6.3 \pm 1 \%$ on BSE $1(P<0.05)$, however, the NUB bulls revealed a marked increase in SEC\% (23.0\% compared to 10.9\%) and the UFB bulls had a modest 
PRM \%: BSE 1 vS BSE 2

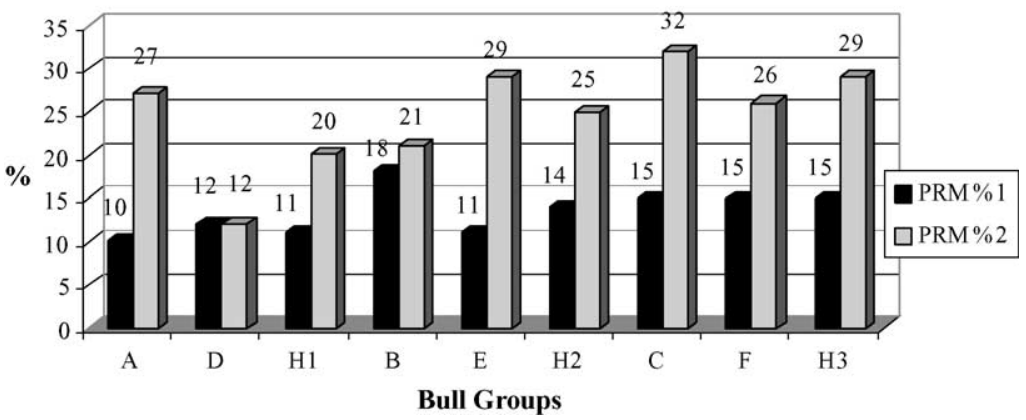

Fig. 2. Changes in percent primary abnormal spermatozoa (PRM\%) in bulls from BSE 1 to BSE 2. HRD and GRP. PRM\% (least square means).

increase (9.7\% compared to $4.7 \%$ ). No differences were found for HRD or R, although R1 had numerically higher SEC\% than R2 $(P=0.09)$, similar to findings with the PRM\% differences. Differences were detected between GRP as well as SBL, with GRP A and C demonstrating higher SEC\% and the AN-, HH-, and LM-SBL having higher SEC\% $(P<0.05)$. The principle secondary defects revealed were detached, normal sperm heads $(8.8 \%)$; refer to Table 6.

Final classification for the 70 bulls available for BSE 2 revealed a significantly lower percentage of bulls achieving satisfactory classification (58.6\%) compared to BSE 1

Table 6

Semen characteristics of bulls (UFB only)

\begin{tabular}{llll}
\hline BSE variables & \multicolumn{2}{l}{ Least square means (S.E.) } & \\
\cline { 2 - 4 } & BSE 2 satisfactory & BSE 2 unsatisfactory & BSE 2 UFB bulls \\
\hline$n$ & 36 & 21 & 57 \\
MOT\% BSE 2 & $62.8(2) \mathrm{a}$ & $40.4(4) \mathrm{b}$ & $54.5(2.5)$ \\
MOT\% BSE 1 & $59.0(2)$ & $59.0(3)$ & $59.4(1.7)$ \\
MRPH\% BSE 2 & $80.6(1) \mathrm{a}$ & $40.0(5) \mathrm{b}$ & $66.2(3.2)$ \\
MRPH\% BSE 1 & $83.3(1)$ & $78.7(3)$ & $81.8(1.3)$ \\
PRM\% BSE 2 & $13.8(1) \mathrm{a}$ & $43.4(3.6) \mathrm{b}$ & $24.7(2.4)$ \\
PRM\% BSE 1 & $12.1(1)$ & $16.6(3.8)$ & $13.5(1.1)$ \\
SEC\% BSE 2 & $5.6(1) \mathrm{a}$ & $16.8(4) \mathrm{b}$ & $9.7(1.6)$ \\
SEC\% BSE 1 & $4.7(1)$ & $4.6(1)$ & $4.7(1)$ \\
Head defects $(\%)$ & $4.0(0.5) \mathrm{a}$ & $9.5(2.0) \mathrm{b}$ & $6.0(0.3)$ \\
Midpiece defects $(\%)$ & $6.2(0.7) \mathrm{a}$ & $11.3(1.7) \mathrm{b}$ & $8.1(0.4)$ \\
Tail defects $(\%)$ & $1.1(0.2)$ & $0.5(0.1)$ & $0.8(0.1)$ \\
Detached heads $(\%)$ & $4.5(0.6) \mathrm{a}$ & $16.3(3.9) \mathrm{b}$ & $8.8(0.5)$ \\
Prox. droplets $(\%)$ & $2.1(0.3) \mathrm{a}$ & $10.8(2.2) \mathrm{b}$ & $5.3(0.2)$ \\
Acrosome defects $(\%)$ & $0.6(0.2)$ & $2.0(0.8)$ & $1.1(0.1)$ \\
Nuclear defects $(\%)$ & $1.0(0.5) \mathrm{a}$ & $9.8(3.5) \mathrm{b}$ & $4.2(0.5)$ \\
\hline
\end{tabular}

Comparison of satisfactory and unsatisfactory bulls. Columns with different letters (a and b) are different $(P<0.05)$.

Analysis of least square means and variances via ANOVA-single factor test.

Analysis of rates and proportions via Chi square test of association; trend analysis, multiple comparisons. 
(90.5\%), $(P<0.01)$. Bulls D4, D6, F4 and one NUB were not available for testing due to injuries that conditionally would result in unsatisfactory classification, reducing the satisfactory-percentage to 55\% for all 74 original bulls. For all 60 UFB bulls, $36(60 \%)$ were classified as satisfactory and $24(40 \%)$ were classified as unsatisfactory on BSE 2, including bull B6 who was originally unsatisfactory on BSE 1; refer to Table 5. Only 5 of 14 NUB bulls were classified as satisfactory (36\%) and all NUB bulls unsatisfactory on BSE $1(n=6)$ remained unsatisfactory on BSE 2 . R1 had less satisfactory bulls than R2, $57 \%$ compared to $70 \%$, respectively $(P<0.05)$. HRD3 had $52 \%$ satisfactory, which was different from HRD1 $(76 \%),(P<0.05)$, and HRD2 had 63\% satisfactory. By GRP, GRP C had only $44 \%$ satisfactory, GRP A, E, F, and B had 56-70\%, and GRP D had 100\% achieve satisfactory classification $(P<0.05)$; refer to Fig. 3 .

No differences in pre-breeding physical characteristics (BW, BCS, HH, Age, SC) were found between bulls classified as satisfactory or unsatisfactory on BSE 2. The satisfactory bulls did have less SC decline $(2.6 \%)$ compared to the unsatisfactory $(3.3 \%)(P<0.05)$ however, no differences in body weight loss during either mating period or total BW loss were evident; refer to Table 7.

Through the breeding season, UFB bulls had body weight losses of $58 \pm 2 \mathrm{~kg}$ during the first mating period (range of 29-91 kg) and $36 \pm 2 \mathrm{~kg}$ during the second mating period (range of 7-75 kg). The UFB bulls completing both mating periods $(n=47)$ incurred a total weight loss of $77 \pm 3 \mathrm{~kg}$ (range of $25-121 \mathrm{~kg}$ ). The total weight loss was equivalent to $13.9 \pm 0.4 \%$ of the BW at the start of the breeding season $(5.1-20.2 \%)$. Bulls in R1 had higher total weight loss than bulls in $\mathrm{R} 2$, during less days of mating exposure $(P<0.05)$. A significant relationship between rotation (breeding season time-period) and BW loss was demonstrated, $r=0.40(P<0.05)$ and total $\mathrm{BW}$ loss was positively associated with $\mathrm{BW}$ at the start of breeding, $r=0.62(P<0.01)$. The 13 UFB bulls removed from mating due to injuries, although only exposed to mating for 5-24 days, incurred total weight loss of $50 \pm 5 \mathrm{~kg}$ or $9.2 \%$ loss of body weight from the starting BW. During the 14-day rest period between mating exposures, $82 \%(n=45)$ of the UFB bulls gained BW of $15 \pm 2 \mathrm{~kg}$ (range of $-18-42 \mathrm{~kg}$ ). BW at the end of the breeding season was $478 \pm 5 \mathrm{~kg}$ (range of 381$548 \mathrm{~kg}$ ), which was less than the non-adjusted average yearling weight for the entire bull population. BCS declined in conjunction with weight loss to $4.6 \pm 0.1$ (range of 4-5 units).

BSE 1 vs. BSE $2 \%$ Satisfactory

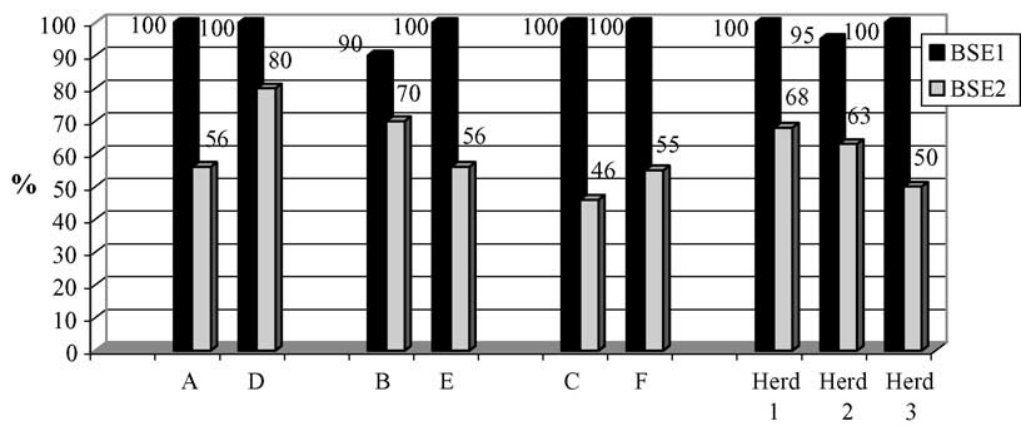

Fig. 3. Bulls classified as satisfactory for BSE 2 and BSE 1. HRD and GRP percentages. 
Table 7

Comparison (physical characteristics) of bulls classified as satisfactory and unsatisfactory for BSE 2

\begin{tabular}{lll}
\hline BSE variables & Least square means (S.E.) & \\
\cline { 2 - 3 } & BSE 2 satisfactory & BSE 2 unsatisfactory \\
\hline$n$ & 36 & 51 \\
BW start (kg) & $548(8)$ & $51.8(0.3)$ \\
HH (in.) & $52.0(0.3)$ & $36.4(0.5)$ \\
SC BSE 1 (cm) & $36.5(0.3)$ & $36.0(0.5)$ \\
SC start (cm) & $35.9(0.3)$ & $34.8(0.5)$ \\
SC end (cm) & $35.0(0.2)$ & $3.30(0.8) \mathrm{b}$ \\
SC chg (\%) & $2.60(0.5)$ a & $59(3)$ \\
BWL1 (kg) & $58(2)$ & $35(1)$ \\
BWL2 (kg) & $35(2)$ & $78(3)$ \\
TWL (kg) & $75(2)$ & $26.9(2)$ \\
Bull-days & $29.0(1)$ & $81 \mathrm{~b}$ \\
Lame $(\%)$ & $58 \mathrm{a}$ & $33 \mathrm{~b}$ \\
Removed $(\%)$ & $8 \mathrm{a}$ &
\end{tabular}

Columns with different letters are different $(P<0.05)$.

Analysis of least square means and variances via ANOVA-single factor test.

Analysis of rates and proportions via Chi square test of association; trend analysis, multiple comparisons.

During the same time period, the NUB bulls gained $27 \pm 8 \mathrm{~kg}$ with a final BW of $585+8 \mathrm{~kg}$ and BCS of 6.2 units; refer to Table 8 .

An unexpected high incidence of lameness and reproductive injuries occurred in the UFB bulls during the breeding season. Total observed cases of lameness were 52 bulls, with

Table 8

Changes in body weight and BCS of bulls during the breeding season UFB and sample groups

\begin{tabular}{|c|c|c|c|c|c|c|c|}
\hline & \multicolumn{7}{|c|}{ Least square means (S.E.) and percentages } \\
\hline & UFB & HRD1 & HRD2 & HRD3 & $\mathrm{R} 1$ & $\mathrm{R} 2$ & Range \\
\hline$n$ & 57 & 19 & 19 & 19 & 28 & 29 & \\
\hline Bull-days & 1651 & 530 & 581 & 540 & 698 & 953 & $5-35$ \\
\hline BWL1 & $58(2)$ & $54(2) \mathrm{a}$ & $69(3) b$ & $51(3) \mathrm{a}$ & $63(2) a$ & $52(2) b$ & $29-91$ \\
\hline BW chg $(\%)$ & $10.5(0.3)$ & $10.1(0.5)$ & $12.4(6)$ & $9.2(0.5)$ & $11.4(0.3)$ & $9.6(0.5)$ & $5.5-14.6$ \\
\hline$n$ & 48 & 14 & 18 & 16 & 22 & 26 & \\
\hline BWL2 & $36(2)$ & $42(3) \mathrm{a}$ & $33(2) b$ & $38(5) \mathrm{a}$ & $35(3)$ & $37(3)$ & $7-75$ \\
\hline TWL & $77(5)$ & $74(5) \mathrm{a}$ & 74 (4) a & $84(6) b$ & $82(5) a$ & 73 (4) b & $25-121$ \\
\hline BW chg $(\%)$ & $13.9(0.4)$ & $13.9(0.9)$ & $13.2(0.6)$ & $14.7(0.9)$ & $14.7(6)$ & $13.3(6)$ & $5.1-20.2$ \\
\hline BW2 & 478 (12) & 458 (12) & 484 (10) & $480(7)$ & 473 (10) & $476(7)$ & $382-548$ \\
\hline $\mathrm{BCS} 2$ & $4.60(0.1)$ & $4.66(0.1)$ & $4.58(0.1)$ & $4.55(0.1)$ & $4.65(0.1)$ & $4.58(0.1)$ & $4-5$ \\
\hline
\end{tabular}

Bull days = total days of bull exposure by bulls/sample. Columns with different letters $(\mathrm{a}$ and $\mathrm{b})$ are different $(P<0.05$ or less). Bull-days, days of bull exposure for bull-group; BWL1, body weight loss during first mating period $(\mathrm{kg})$; BW chg. $(\%)$, percentage BW change from starting BW; BWL2, body weight loss during second mating period $(\mathrm{kg})$; TWL, total body weight loss through breeding season $(\mathrm{kg})$; BW2, non-shrunk BW at end of breeding season $(\mathrm{kg})$; BCS2, body condition score at end of breeding season.

Analysis of least square means and variance via ANOVA-single factor test.

Analysis of frequencies via Chi square test of association; trend analysis, adj residuals. 
38 of the bulls observed lame at least once (63\%) and 14 bulls lame more than once $(23 \%)$. As for reproductive injuries, 7 of the 60 bulls (12\%) incurred prepucial or penile injuries, of which three cases were detected during the mating exposures and four were detected following the breeding season. Overall, 45 bulls (75\%) incurred injuries and $13(22 \%)$ were removed prior to the completion of the season. Three bulls were added as replacements during the first mating period only. Of the 60 UFB bulls, $47(78 \%)$ remained at the completion of the breeding season, although $16(34 \%)$ were lame and four had existing reproductive injuries. No injuries causing lameness were observed in the NUB bulls and one bull had testicular abnormalities. The incidence rates of lameness were $53 \%$ for R 1 and $73 \%$ for R2 $(P=0.11)$, however more of the cases of lameness in R2 were considered minor and occurred late in the season. Herd incidence rates ranged from $47 \%$ in HRD2, to $68 \%$ in HRD3 and $74 \%$ in HRD1 $(P=0.20)$. Differences in injury rates were present between bull sample-groups and sire-breed lines $(P<0.05)$. No significant associations were evident for injuries or injury rates with any physical or pre-breeding reproductive traits. However, bulls used in HRD1 (GRP A and D), having the highest overall injury rate (74\%), revealed a significant rank correlation for injury score with hip height, $r=0.62$ and body weight, $r=0.54(P<0.05)$, whereas similar associations were not detected in the other two herd-groups of bulls.

The bulls classified as unsatisfactory on BSE 2 had a disproportionate level of injuries and bulls removed due to injuries, with $81 \%$ of these bulls incurring injuries and $33 \%$ being removed prior to the end of the mating season, compared to $58 \%$ injury rate and $8 \%$ removal-rate for the bulls classified as satisfactory $(P<0.01)$. Including the three injured individuals not available for BSE 2 would widen this difference; refer to Table 7.

Pregnancy rates were not significantly different between herds: HRD1 $=93.3 \%$, HRD2 $=91.6 \%$ and HRD3 $=95.4(P=0.32)$. Similarly, no differences in calving rates were revealed between herds: $91.2,89.5$ and $93.4 \%$, respectively. No differences in calving rates during the first, second or third 21-day periods of the calving season were detected between herds; refer to Table 9a. Utilizing calving dates and estimated date of conception, calves sired by GRP were estimated. Although numerical differences in percentage of calves born per exposed female were evident, no differences $(P>0.05)$ were demonstrated

Table 9a

Pregnancy rates of HRD and calving rates by mating period for each herd

\begin{tabular}{|c|c|c|c|c|}
\hline & \multicolumn{4}{|c|}{ Percentages and frequency counts } \\
\hline & HRD1 & HRD2 & HRD3 & $P$ \\
\hline$n$ & 194 & 191 & 196 & \\
\hline Pregnancy rate & $93.30 \%$ & $91.60 \%$ & $95.40 \%$ & 0.32 \\
\hline \multicolumn{5}{|c|}{ Calving percentage ${ }^{\mathrm{a}}$ ( $\%$ of total herd) } \\
\hline Period 1 & $80(41.2)$ & $64(33.5)$ & $71(36.2)$ & 0.28 \\
\hline Period 2 & $50(25.8)$ & $54(28.3)$ & $68(34.7)$ & 0.14 \\
\hline Period 3 & $28(14.4)$ & $25(13.1)$ & $30(15.3)$ & 0.82 \\
\hline Period 4 & $18(9.30) \mathrm{a}$ & $28(14.7) \mathrm{b}$ & $14(7.10) \mathrm{a}$ & 0.04 \\
\hline
\end{tabular}

Analysis performed via Chi square test of association. Values in parentheses are percentages.

Columns with different letters $(\mathrm{a}$ and $\mathrm{b})$ are different $(P<0.05)$.

${ }^{\text {a }}$ Calves born per period per total females exposed for breeding. 
Table $9 \mathrm{~b}$

Estimated calving rates by mating periods $(P)$ for GRP Calving rates for females available to become pregnant during corresponding mating periods

\begin{tabular}{|c|c|c|c|c|c|c|c|c|c|c|c|c|}
\hline & \multirow{2}{*}{$\begin{array}{l}\text { HRD1 } \\
\text { GRP }\end{array}$} & \multicolumn{3}{|c|}{ Females calves } & \multirow[t]{2}{*}{ HRD2 GRP } & \multicolumn{3}{|c|}{ Females calves } & \multirow{2}{*}{$\begin{array}{l}\text { HRD3 } \\
\text { GRP }\end{array}$} & \multicolumn{3}{|c|}{ Females calves } \\
\hline & & Available & Born & $\%$ & & Available & Born & $\%$ & & Available & Born & $\%$ \\
\hline P1 & A & 194 & 80 & 41 & B & 191 & 64 & 34 & $\mathrm{C}$ & 196 & 71 & $36^{\mathrm{a}}$ \\
\hline $\mathrm{P} 2$ & $\mathrm{D}$ & 114 & 50 & 44 & $\mathrm{E}$ & 127 & 54 & 43 & $\mathrm{~F}$ & 125 & 68 & 54 \\
\hline P3 & A & 64 & 28 & 44 & B & 73 & 25 & 34 & $\mathrm{C}$ & 57 & 30 & 53 \\
\hline $\mathrm{P} 4$ & $\mathrm{D}$ & 36 & 18 & 50 & $\mathrm{E}$ & 48 & 28 & $58^{\mathrm{a}}$ & $\mathrm{F}$ & 27 & 14 & 52 \\
\hline
\end{tabular}

Analysis via Chi square test of association and trend analysis of proportions.

Females available to conceive during each subsequent mating period.

Calves born during corresponding calving period.

$\%$, percent of calves born per available cow to conceive per period (calving rate).

${ }^{a}$ Denotes percentage differences between mating periods within herd only.

for bull-groups during the first three mating periods, however, GRP E did have higher numbers of calves born during the last 21 days of the calving season when compared to GRP D and F $(P<0.05)$; refer to Table $9 \mathrm{~b}$. More concise and specific information on bull reproductive performance will be elucidated with DNA-genotyping of the offspring, sires and dams to assign parentage to each individual calf.

\subsection{Environmental conditions prior to and during the breeding season}

At the time of BSE 1 (May 16, 2002), average daily temperatures had been below normal for 13 of the prior 16 days (range from 46 to $69^{\circ} \mathrm{F}$ ). Mean daily-temperature for the month of May was $59^{\circ} \mathrm{F}, 2.7^{\circ} \mathrm{F}$ below normal with the average maximum-temperature of $70{ }^{\circ} \mathrm{F}$. At the end of the month and the first 2 days of June, five continuous days of temperatures $8-18{ }^{\circ} \mathrm{F}$ higher than normal occurred, with average daily high-temperatures of $90-99^{\circ} \mathrm{F}$ and average daily-temperatures of $74-86^{\circ} \mathrm{F}$. Another 4 days of higher than normal daily-temperatures occurred during the turnout time of R1 bulls, with $>90{ }^{\circ} \mathrm{F}$ average daily-highs and $>75^{\circ} \mathrm{F}$ average daily-temperatures. During the turnout period for $\mathrm{R} 2$ bulls, average daily high-temperatures exceeded $90^{\circ} \mathrm{F}$ for 10 days and average dailytemperatures exceeded $78{ }^{\circ} \mathrm{F}$. The average daily-temperature for June was $77^{\circ} \mathrm{F}$ and average maximum-temperature was $90{ }^{\circ} \mathrm{F}$, with 19 days exceeding $90{ }^{\circ} \mathrm{F}$. Precipitation during the month of May 2002 was 1.12 in. below normal and during June was 2.64 in. below normal.

The average daily temperatures, average daily high temperatures, and maximum high temperatures are charted in Fig. 4. The reference climate period was from 1971 to 2000.

During the first mating period of R1, 7 of the 14 days for each of GRP A, B and C had daily high temperatures greater than $90{ }^{\circ} \mathrm{F}$ and daily low temperatures greater than $70^{\circ} \mathrm{F}$, with 11 days of maximum high temperatures from 90 to $97^{\circ} \mathrm{F}$. Average daily temperature rose from $70{ }^{\circ} \mathrm{F}$ during Week- 1 to $80{ }^{\circ} \mathrm{F}$ during Week-2. Only a trace of precipitation was recorded and relative humidity ranged from 30 to $58 \%$.

During the first mating period for R2, 10 of the 14 days for each of GRP D, E and F had daily high temperatures greater than $90{ }^{\circ} \mathrm{F}$ and daily low temperatures greater than $70{ }^{\circ} \mathrm{F}$, 


\begin{tabular}{lllllllllllll} 
& \multicolumn{1}{c}{ BSE 1 } & $\begin{array}{l}\text { Pre- } \\
\end{array}$ & & Wk 1 & Wk 2 & Wk 3 & Wk 4 & Wk 5 & Wk 6 & Wk 7 & Wk 8 & Wk 9 \\
\cline { 2 - 12 } & & ABC & & DEF & & ABC & & DEF & & \\
Ave Daily Temp & 43 & 73 & 70 & 80 & 82 & 80 & 76 & 84 & 78 & 80 & 76 \\
Ave Daily High & 48 & 85 & 81 & 92 & 95 & 90 & 86 & 97 & 90 & 93 & 89 \\
Max High & 48 & 99 & 91 & 97 & 97 & 93 & 100 & 102 & 97 & 100 & 97 \\
Days $>90$ & 0 & 7 & 1 & 6 & 7 & 5 & 2 & 7 & 4 & 5 & 8 \\
\hline
\end{tabular}

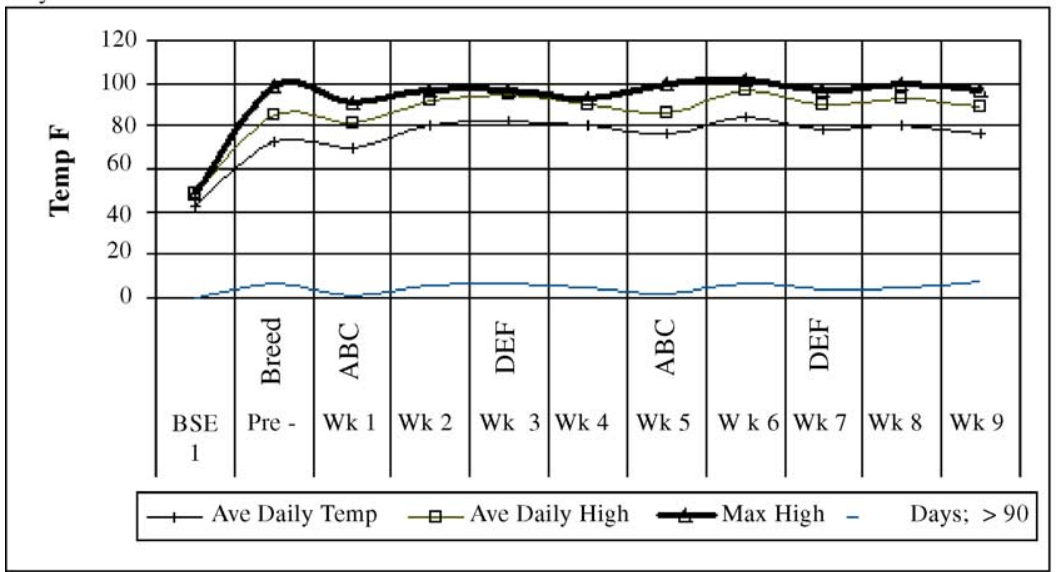

$\mathrm{Wk}=$ week of breeding season

Recorded at National Weather Service Regionla Center, Hastings, NE, USA.

$\mathrm{ABC}=\mathrm{R} 1 \quad \mathrm{DEF}=\mathrm{R} 2$

Fig. 4. Weekly average air temperature readings for bull breeding season. (temperatures in ${ }^{\circ} \mathrm{F}$ ).

with 12 days of maximum high temperatures from 90 to $101{ }^{\circ} \mathrm{F}$. Average daily temperatures for the two-week period was $80-82{ }^{\circ} \mathrm{F}$. No precipitation was recorded and relative humidity ranged from 30 to $50 \%$.

During the second mating period for R1, 8 of the 14 days had daily high temperatures greater than $90{ }^{\circ} \mathrm{F}$ and daily low temperatures greater than $70{ }^{\circ} \mathrm{F}$, with 10 days of maximum high temperatures from 90 to $104{ }^{\circ} \mathrm{F}$. Average daily temperature for week 5 was 76 and $84{ }^{\circ} \mathrm{F}$ for week 6 . Only a trace of precipitation was recorded and average relative humidity ranged from 25 to $60 \%$.

During the second mating period for R2, 10 of the 21 days had daily high temperatures greater than $90{ }^{\circ} \mathrm{F}$ and daily low temperatures greater than $70{ }^{\circ} \mathrm{F}$, with 15 days of maximum high temperatures from 90 to $104^{\circ} \mathrm{F}$. Average daily temperatures were near $80^{\circ} \mathrm{F}$ for each week. Precipitation was recorded on 6 days, totaling 1.9 in. of rain and relative humidity ranged from 30 to $60 \%$ on the days not recording precipitation.

Overall, the 63-days breeding season had 13 days with daily temperatures greater than $10^{\circ}$ above normal and 37 days with daily high temperatures greater than $90^{\circ} \mathrm{F}$. Day 7 through 24 was an extended period of higher than normal ambient temperatures, with daily-highs above $88^{\circ} \mathrm{F}\left(88-101^{\circ} \mathrm{F}\right)$ and minimal nighttime cooling $\left(65-75^{\circ} \mathrm{F}\right)$. From Days 32-35, a 3-day period of marked above normal temperatures occurred consecutively as well as a 6-day period from Days 47-52. Precipitation was 6 in. below normal for the entire breeding season. 
As a subjective observation, native-grass and cool-season grass pasture conditions deteriorated through the breeding season and forage availability was reduced due to the extended dry-period commencing the previous year. Herds on irrigated pastures (HRD1 and 2) had access to more readily available forage of potentially higher nutritive quality. Bulls in HRD3 had access to native forages only throughout the breeding season. The forage quality of the pastures where the NUB bulls were maintained was similarly influenced by the climatic conditions, however, supplemental feed was provided late in the season.

\section{Discussion}

Results from this study reveal that yearling beef bulls of uniform age and similar prebreeding physical and reproductive attributes experience considerable changes during natural mating and within seasonal environmental conditions. Loss of body weight and condition during mating is a consistent finding in other studies and was attributed to such factors as; pre-breeding physical condition, excessive physical activity during mating and reduced nutritional intakes, particularly during the early season when the mating loads are heavier $[12,29,33]$. Exposure of the UFB bulls to mating and the associated increased physical activity contributed to marked physical changes, whereas, the NUB bulls, under similar environmental conditions, maintained physical condition as expected. UFB bulls incurred higher BW losses during the early portions of mating, demonstrating rapid physical changes when mating activity would be expected to be highest. Environmental conditions and available nutrition from the breeding pastures may have contributed to the physical changes.

In conjunction with physical changes, changes in reproductive characteristics in both the UFB and NUB bulls were revealed. The declines in SC in UFB bulls, from the initial $\mathrm{BSE}$ and prior to any mating exposure, have been similarly reported in yearling bulls following performance testing [34]. Changes of this nature have been attributed to seasonal effects of increasing ambient temperatures [35]. Loss of scrotal fat depositions associated with body condition declines and stress-induced depression of testicular function have also been incriminated as contributing factors for SC declines following environmental and management changes $[17,19]$. The positive association of SC declines with BW losses, in conjunction with the finding of increases in SC in the NUB bulls with BW gains, demonstrates the linkage of SC to body condition. Although bulls with heavier prebreeding body weights lost higher percentages of BW and SC, no assessment of differences in scrotal fat was undertaken to evaluate the association of body weight with scrotal fat content and possible relationships with SC changes. Body weight losses in young bulls would be indicative of physiological stress and insufficient nutritional intakes to meet growth and activity demands, both of which could lead to stress-induced testicular changes. Seasonal effects, scrotal fat declines during periods of BW declines, and stress-induced effects are all potential explanations for SC changes as demonstrated in this study.

The magnitude of physical and reproductive injury rates in UFB bulls was unexpected. Prevalence rates of injuries to bulls during mating are undocumented, however, the risks and occurrence of injury to yearling bulls are not unexpected. Reasons for the high 
incidence in this study are unclear and only limited evidence of association to prebreeding physical characteristics was revealed. Overall, no single phenotypic or genotypic trait was demonstrated to be associated with injury occurence, however, small and unequal sample groups limited expression of significant findings. Breeding herd, bullgroup and sire-breed line differences were evident. The severity of injury was higher during the early mating periods and visual observations would suggest inexperienced mating ability and over-aggressive sexual and social behaviors as contributing to injury events. Injuries during the later mating periods, although occurring at higher rates, were less severe and could have been related to physical fatigue and stress. No clear explanation for the phenomenon was revealed. Injuries incurred during the mating season did influence the availability of physically sound bulls within mating periods, however, no significant differences in bull-group pregnancy rates were demonstrated. Pregnancy rate similarities were probably sustained with the expanded bull-to-female mating ratios afforded by the rotational mating design and less than heavy mating loads. Individual bull reproductive performance was undoubtedly altered, specifically in bulls removed early from the mating season.

The negative changes in seminal quality, revealed in individual bulls following the mating season were primarily associated with increases in abnormal spermatozoa. Sperm motility changes were highly associated to morphological abnormalities. The demonstration of these seminal changes illustrates the potential for change in fertility of yearling bulls during mating conditions. Similar changes in seminal quality have been reported in newly purchased bulls following acquisition and environmental and management changes [19] and in bulls with induced temperature and stress conditions $[18,21]$. In this study, declining reproductive potential of nearly $50 \%$ of the individual UFB bulls was demonstrated with findings of reduced spermatozoal motility and marked increases in both primary and secondary abnormal spermatozoa. Loss of body weight and declines in SC were not significantly associated with the seminal changes. However, UFB bulls classified as unsatisfactory had significantly larger declines of SC, which suggests testicular changes contributing to reduced semen quality. The demonstration of similar seminal quality changes in NUB bulls with prior satisfactory classification, in conjunction with $\mathrm{BW}$ and $\mathrm{SC}$ increases, suggests a common factor other than physical condition changes as influencing aberrant sperm production in both UFB and NUB bulls. High climatic temperatures, particularly during the early periods of the mating season, potentially inflicted adverse effects on spermatozoal production. This was the principal factor common for bulls used for mating and those not exposed. The effect of climate on nutritional conditions of pastures was not assessed to determine any added effects. Both UFB and NUB bulls demonstrated spermatozoal abnormalities consistent with climatic temperature-induced testicular dysfunction [21].

In summary, although body weight and condition declines were not different between UFB bulls classified as satisfactory or unsatisfactory, the occurrence of weight loss during mating activity was indicative of physiologic stress. Rapid weight loss during the early mating periods, in association with high mating activity and elevated climatic temperatures imposed a compounding of stressors upon testicular function and sperm production. Furthermore, the significant negative influence of injury on seminal quality parameters and BSE-classification indicates the potential effects associated with pain and stress related to 
the injuries. Bulls with induced stress conditions and injuries [17,18,21] have demonstrated similar seminal changes as revealed in this study. Individual bulls demonstrated variable responses to physiological and environmental stressors and seminal characteristics were influenced in similarly variable degrees.

Fertility-potential of yearling beef bulls is dependent on the interaction and relationships of multiple physical, reproductive and behavioral factors. In addition, the environmental and management conditions imposed upon young bulls may favorably or unfavorably influence reproductive capability. Within the conditions of this study, yearling beef bulls of satisfactory fertility-potential prior to a mating season incurred marked physical and reproductive changes from the physiologic stress of mating activity, adverse environmental conditions and effects of injuries. The breeding soundness status of nearly $50 \%$ of the bulls declined through the mating season to standards considered less than satisfactory for expected mating performance. However, reproductive performance within the breeding herd was sustained at acceptable levels due to sufficient fertility of individual bulls through the course of the mating season and moderate mating loads. Undoubtedly, individual bulls contributed differently to the herd reproductive results due to the altered physical and reproductive characteristics and variable responses to the factors identified as affecting fertility. Further investigation will elucidate individual bull reproductive performance under the conditions imposed by this study and individual bull responses to the environmental impacts.

\section{References}

[1] Guidelines for using the Bull Breeding Soundness Evaluation Form. In: Theriogenology Handbook. Society for Theriogenology; 1993, p. B-10.

[2] Chenoweth PJ, Hopkins FM, Spitzer JC, Larsen RE. New guidelines for the evaluation of bulls for breeding soundness. Proc Bovine Pract 1994;27:105-7.

[3] Kennedy SP, Spitzer JC, Hopkins FM, Higdon III HL, Bridges WC. Breeding soundness evaluations of 3648 yearling beef bulls using the 1993 Society for Theriogenology guidelines. Theriogenology 2002;58:947-61.

[4] Spitzer JC, Hopkins FM. Bull fertility. Breeding soundness evaluation of yearling bulls. In: The veterinary clinics of North America. Food animal practice. Philadelphia: WB Saunders Co., July 1997.

[5] Farin PW, Chenoweth PJ, Tomky DF, Pexton JE. Breeding soundness, libido and performance of beef bulls mated to estrus-synchronized heifers. Theriogenology 1989;32:717-25.

[6] Wiltbank JN, Parish NR. Pregnancy rate in cows and heifers bred to bulls selected for semen quality. Theriogenology 1986;25:779-83.

[7] Chenoweth PJ. Rationale for using bull breeding soundness evaluations. Comp Contin Educ Pract Vet 2000;22:S48-55.

[8] Chenoweth PJ. Libido, breeding soundness and fertility of range bulls. In: Proceedings of the Annual Meeting of Society for Theriogenology; 1978. p. 65-71.

[9] Almquist JO, Branas RJ, Barber KA. Postpubertal changes in semen production of Charolais bulls ejaculated at high frequency and the relation between testicular measurement and sperm output. J Anim Sci 1976;42:670.

[10] Chase Jr CC, Chenoweth PJ, Larsen RE. Growth and reproductive development from weaning through 18months of age among breeds in sub-tropical Florida. Theriogenology 1997;47:723-45.

[11] Coulter GH. Puberty and postpubertal development of beef bulls. In: Morrow DA., editor. Current therapy in Theriogenology2nd ed., Philadelphia: WB Saunders Co.; 1986. p. 142.

[12] Corah LR. Nutritional and reproductive management of bulls. Agric Pract 1987;8:7-37. 
[13] Lunstra DD, Ford JJ, Echternkamp SE. Puberty in beef bulls: hormone concentrations, growth, testicular development, sperm production and sexual aggressiveness in bulls of different breeds. J Anim Sci 1978;46:1054-62.

[14] Coe PH. Associations among age, scrotal circumference, and proportion of morph-ologically normal spermatozoa in young beef bulls during an initial breeding soundness examination. J Am Vet Med Assoc 1999;214:1664-7.

[15] Cates WF. Observations on scrotal circumference and its relationship to classification of bulls. In: Proceedings of the Annual Meeting of Society for Theriogenology; 1975. p. 9-27.

[16] Gipson TA, Vogt DW, Massey JW, et al. Associations of scrotal circumference with semen traits on young beef bulls of different breeds. J Anim Sci 1986;24:217-25.

[17] Barth AD, Waldner CL. Factors affecting breeding soundness classification of beef bulls examined at the Western College of Veterinary Medicine. Can Vet J 2002;43:274-84.

[18] Barth AD, Bowman PA. The sequential appearance of sperm abnormalities after scrotal insulation or dexamethasone treatment in bulls. Can Vet J 1994;35:93-102.

[19] Barth AD, Cates WF, Harland RJ. The effect of body fat and loss of fat on breed-ing soundness classification of beef bulls. Can Vet J 1995;36:758-64.

[20] Coulter GH, Carruthers RP, Amann RP, Kozub GC. Testicular development, daily sperm production and epididymal sperm reserves in 15-month old Angus and Hereford bulls: effects of bull strain plus dietary energy. J Anim Sci 1987;64:254-60.

[21] Meyerhoeffer DC, Wettemann RP, Coleman SW, Wells ME. Reproductive criteria of beef bulls during and after exposure to increased ambient temperature. J Anim Sci 1985;60:352-7.

[22] Barth AD, Oko RJ. Abnormal morphology of bovine spermatozoa. Ames, IA: Iowa State University Press, 1989.

[23] Boyd GW, Lunstra DD, Corah LR. Serving capacity of crossbred yearling beef bulls. I. Single sire mating behavior and fertility during average and heavy mating loads at pasture. J Anim Sci 1989;67:60-71.

[24] Boyd GW, Healy VM, Mortimer RG, Piotrowski JR. Serving capacity tests are unreliable to predict the fertility of yearling bulls. Theriogenology 1991;36:1015-25.

[25] Corah LR, Kiracofe GH, McKee M, Schalles RR. Evaluating the breeding potential of yearling bulls. J Anim Sci 1979;49(Suppl. 1):288.

[26] Godfrey RW, Lunstra DD. Influence of single or multiple sires and serving capacity on mating behavior of beef bulls. J Anim Sci 1989;67:2897-903.

[27] Chenoweth PJ, Chase Jr CC, Thatcher MJD. Wilcox CJ, Larsen RE. Breed and other effects on reproductive traits and breeding soundness categorization in young beef bulls in Florida. Theriogenology 1996;46:1159_ 70 .

[28] Godfrey RW, Randel RD, Lunstra DD, Berardinelli JG. The effect of environment upon reproductive function of Brahman and Hereford bulls. In: Proceedings of the Annual Meeting of Society for Theriogenology; 1987. p. 32-55.

[29] Ellis, RW. Changes in physical, reproductive and behavioral characteristics of yearling beef bulls during natural service. M.S.Thesis. Lincoln: University of Nebraska; 2004.

[30] Ball L, Nelson LD, Furman JW. Semen collection and evaluation of bulls for breeding soundness. Study of breeding soundness. In: Proceedings of the Annual Meeting of Society for Theriogenology; 1974.

[31] Sincich T, Levine DM, Stephan D. Practical statistics by example using Microsoft Excel. Upper Saddle, NJ: Prentice-Hall, 1999.

[32] Abramson JH, Gahlings PH. Computer programs for epidemiologists. PEPI Version 4.0. Salt Lake City: Sagebrush Press, 2001.

[33] Chenoweth PJ. Objectives and outcomes from selection and management of fertile bulls. In: Bull fertility: selection and management in Australia. Indooroophilly Q: Australian Association of Cattle Veterinarians, 2002 [Chapter 1].

[34] Makarechian MA, Farid A, Berg RT. Relationships between growth parameters and scrotal circumference in young beef bulls. Theriogenology 1984;22:667-74.

[35] Fields MJ, Burns WC, Warnick AC. Age, season and breed effects on testicular volume and semen traits in young beef bulls. J Anim Sci 1979;48:1299-304. 